\title{
MATHEMATICAL MODEL FOR OPTIMIZATION OF HEAT EXCHANGE SYSTEMS OF A REFINERY
}

\author{
Vladimir Aleksandrovich Lebedev ${ }^{1, *}$, and Ekaterina Aleksandrovnal Yushkova ${ }^{1}$ \\ ${ }^{1}$ Saint-Petersburg Mining University, 2, 21st Line, St Petersburg 199106, Russia
}

\begin{abstract}
The article is devoted to the issue of thermodynamic optimization of heat transfer systems. Optimization is carried out by an exergy pinch method. This method includes the advantages of exergy analysis and pinch method. Exergy analysis takes into account the quantitative and qualitative characteristics of thermal processes, the pinch method allows structural and parametric optimization of heat transfer systems. The article presents a mathematical model for optimization by exergy pinch analysis. This model allows automated system optimization. Exergy pinch analysis allows more efficient use of energy and resources at the enterprise, which is relevant today.
\end{abstract}

\section{Introduction}

Russia is the largest exporter of oil and gas, increasing the efficiency of the refinery is an urgent task requiring a thorough scientific approach to their study $[1,2]$. An oil refinery is a complex heat and power facility in which there are processes of heat generation and its use in production.

The exergy method of thermodynamic analysis allows one to take into account the energy potential (qualitative characteristics) of thermal processes [3, 4, 5, 6]. To date, the most effective method of parametric optimization of heat and power processes is the method of integration of heat fluxes (pinch method) [7, 8]. However, the pinch method is based on a change in enthalpy, which does not take into account the qualitative characteristics of energy [9]. In our article, the development of the pinch method continues; exergy is used instead of enthalpy. Heat exchange systems are optimized by using the exergy pinch method.

Earlier, we performed an exergy pinch analysis of the heat exchange system of the boiler unit and analysis of the heat exchange system of the primary oil refining unit $[10,11]$. The results of the analysis of the exergy pinch allow us to formulate and justify specific design measures to improve the energy efficiency of heat transfer systems, which is very important for the oil refining industry $[12,13]$.

\section{Mathematical model}

The heat exchange system is optimal when the exergy losses are minimal (1):

$$
\sum \Delta E \rightarrow \min
$$

where $\sum \Delta E$ - the sum of the exergy losses in the system.

To fulfill this condition, it is necessary that the recovery of exergy of hot and cold flows is maximum; therefore, the difference between exergies of hot and cold flows tends to a minimum.

In most cases, external energy carriers are necessary for the operability of the heat exchange system. They, in turn, impose a financial burden on the enterprise. Thus, the sum of exergies of external hot and cold energy carriers (utilities) must be minimized.

In view of the above, in order to optimize the heat exchange system, in addition to bringing the composite curves closer to the minimum temperature difference $\Delta$ Tmin, use the following function (2):

$$
\begin{aligned}
& \sum \Delta E=\left|e_{h}\right|-\left|e_{c}\right|+\left|E_{U H}\right|-\left|E_{U C}\right| \\
& \left|e_{h}\right|-\left|e_{c}\right| \rightarrow \min \\
& \sum E_{U H} \rightarrow \min \\
& \sum E_{U C} \rightarrow \min
\end{aligned}
$$

where $e_{h}$ - the exergy of the hot composite curve,

$e_{c}$ - exergy of the cold composite curve,

$E_{U H}$ - exergy of external hot energy carriers,

$E_{U C}$ - exergy of external cold energy carriers,

Limitations:

- for hot streams $\mathrm{T}_{\mathrm{h} 1}<\mathrm{T}_{\mathrm{h} 2}<\ldots<\mathrm{T}_{\mathrm{h}(\mathrm{k}-1)}<\mathrm{T}_{\mathrm{hk}}$, - for cold flows $\mathrm{T}_{\mathrm{c} 1}<\mathrm{T}_{\mathrm{c} 2}<\ldots<\mathrm{T}_{\mathrm{c}(\mathrm{k}-1)}<\mathrm{T}_{\mathrm{ck}}$.

One of the main stages of an exergy pinch analysis is the determination of composite curves [14, 15]. Manual

\footnotetext{
* Corresponding author: lebedev va@spmi.ru
} 
determination takes a lot of time, and the human factor cannot be avoided.

The approach to the mathematical model of traditional pinch analysis was developed by D. Agapov. A mathematical model can be used to determine exergetic composite curves. This mathematical model is suitable for flows without phase transitions. The initial data for the model are formed in the form of three matrices. The first matrix includes the source data of the hot stream (Hot), the second matrix includes the source data of the cold stream (Cold). The number of hot flows is $\mathrm{n}$, the number of cold flows is $\mathrm{m}$. These two matrices indicate: the initial and final temperatures of the flows, the ambient temperature, the natural logarithm of the ratio of the initial and final temperatures of the flows, and also the flow heat capacity (the product of the specific heat capacity and mass flow rate). The unit of temperature is Kelvin. Ambient temperature is a constant parameter for the entire system. The third matrix consists of the original values of the first two columns of the matrices $\mathrm{E}_{\mathrm{H}}$ and $\mathrm{E}_{\mathrm{C}}$. Moreover, all temperatures in this basis are sorted in ascending order, i.e. $\mathrm{T}_{1}<\mathrm{T}_{2}<\ldots<\mathrm{T}_{\mathrm{k}-1}$ $<\mathrm{T}_{\mathrm{k}}$.

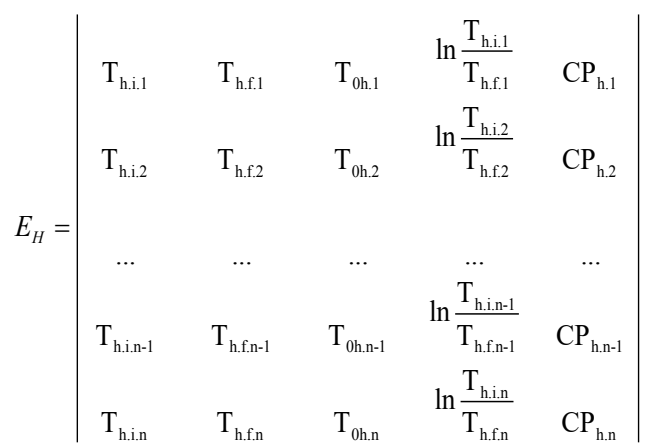

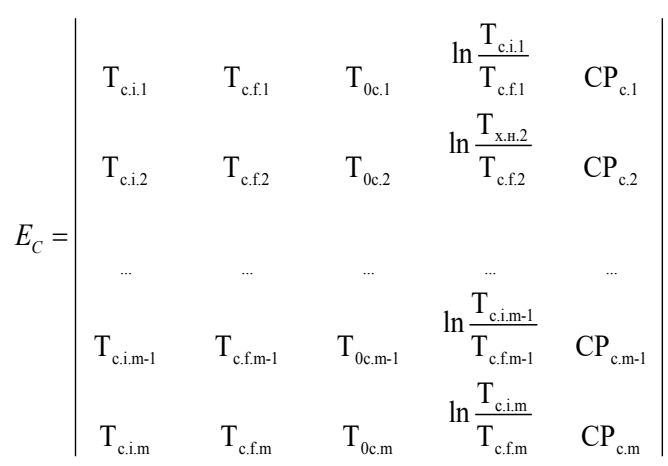

$$
\begin{aligned}
& T_{H \cup C}=\left|\begin{array}{c}
T_{1} \\
T_{2} \\
\ldots \\
T_{k-1} \\
T_{k}
\end{array}\right|
\end{aligned}
$$

Functional dependencies forming a composite curve of hot flows have the form (6):

- for the first temperature range:

$$
e_{h}=\left.\left(\mathrm{T}_{\mathrm{h} 2}-\mathrm{T}_{\mathrm{h} 1}-\mathrm{T}_{\mathrm{o}} \ln \frac{\mathrm{T}_{\mathrm{h} 2}}{\mathrm{~T}_{\mathrm{h} 1}}\right) \sum_{\mathrm{i}=1}^{\mathrm{n}} \mathrm{CP}_{\mathrm{hi}}\right|_{\mathrm{T}_{\mathrm{h} 1}} ^{\mathrm{T}_{\mathrm{h} 2}}, \mathrm{~T}_{\mathrm{h} 1}<\mathrm{T}_{\mathrm{h} 2} ;
$$

- for the first and second temperature ranges:

$$
\begin{aligned}
& e_{h}=\left.\left(\mathrm{T}_{\mathrm{h} 2}-\mathrm{T}_{\mathrm{h} 1}-\mathrm{T}_{\mathrm{o}} \ln \frac{\mathrm{T}_{\mathrm{h} 2}}{\mathrm{~T}_{\mathrm{h} 1}}\right) \sum_{\mathrm{i}=1}^{\mathrm{n}} \mathrm{CP}_{\mathrm{hi}}\right|_{\mathrm{T}_{\mathrm{h} 1}} ^{\mathrm{T}_{\mathrm{h} 2}}+ \\
& +\left.\left(\mathrm{T}_{\mathrm{h} 3}-\mathrm{T}_{\mathrm{h} 2}-\mathrm{T}_{\mathrm{o}} \ln \frac{\mathrm{T}_{\mathrm{h} 3}}{\mathrm{~T}_{\mathrm{h} 2}}\right) \sum_{\mathrm{i}=1}^{\mathrm{n}} \mathrm{CP}_{\mathrm{h} 1}\right|_{\mathrm{T}_{\mathrm{h} 2}} ^{\mathrm{T}_{\mathrm{h} 3}}, \mathrm{~T}_{\mathrm{h} 1}<\mathrm{T}_{\mathrm{h} 2}<\mathrm{T}_{\mathrm{h} 3}
\end{aligned}
$$

- for (k-1) temperature ranges:

$$
\begin{aligned}
& e_{h}=\sum_{j=1}^{j=k-1}\left[\left.\left(\mathrm{~T}_{\mathrm{hj}}-\mathrm{T}_{\mathrm{h}(\mathrm{j}-1)}-\mathrm{T}_{\mathrm{o}} \ln \frac{\mathrm{T}_{\mathrm{hj}}}{\mathrm{T}_{\mathrm{h}(\mathrm{j}-1)}}\right) \sum_{\mathrm{i}=1}^{\mathrm{n}} \mathrm{CP}_{\mathrm{hi}}\right|_{\mathrm{T}_{\mathrm{h}(\mathrm{k}-1)}} ^{\mathrm{T}_{\mathrm{hj}}}\right]+ \\
& +\left.\left(\mathrm{T}_{\mathrm{hk}}-\mathrm{T}_{\mathrm{h}(\mathrm{k}-1)}-\mathrm{T}_{\mathrm{o}} \ln \frac{\mathrm{T}_{\mathrm{hk}}}{\mathrm{T}_{\mathrm{h}(\mathrm{k}-1)}}\right) \sum_{\mathrm{i}=1}^{\mathrm{n}} \mathrm{CP}_{\mathrm{hi}}\right|_{\mathrm{T}_{\mathrm{h}(\mathrm{k}-1)}} ^{\mathrm{T}_{\mathrm{hk}}}, \mathrm{T}_{\mathrm{h}(\mathrm{k}-2)}<\mathrm{T}_{\mathrm{h}(\mathrm{k}-1)}<\mathrm{T}_{\mathrm{hk}}
\end{aligned}
$$

- for $\mathrm{k}$ temperature ranges:

$$
e_{h}=\sum_{j=1}^{j=k}\left[\left.\left(\mathrm{~T}_{\mathrm{hj}}-\mathrm{T}_{\mathrm{h}(\mathrm{j}-1)}-\mathrm{T}_{\mathrm{o}} \ln \frac{\mathrm{T}_{\mathrm{hj}}}{\mathrm{T}_{\mathrm{h}(\mathrm{j}-1)}}\right) \sum_{\mathrm{i}=1}^{\mathrm{n}} \mathrm{CP}_{\mathrm{hi}}\right|_{\mathrm{T}_{\mathrm{h}(\mathrm{h}-1)}} ^{\mathrm{T}_{\mathrm{j}}}\right], \mathrm{T}_{\mathrm{h}(\mathrm{k}-1)}<\mathrm{T}_{\mathrm{hk}}(6)
$$

where $\mathrm{n}$ is the number of heat flows in a given interval

The functional dependencies that form the composite cold flows have the form (7):

- for the first temperature range:

$$
e_{c}=\left.\left(\mathrm{T}_{\mathrm{c} 2}-\mathrm{T}_{\mathrm{c} 1}-\mathrm{T}_{\mathrm{o}} \ln \frac{\mathrm{T}_{\mathrm{c} 2}}{\mathrm{~T}_{\mathrm{c} 1}}\right) \sum_{\mathrm{i}=1}^{\mathrm{n}} \mathrm{CP}_{\mathrm{ci}}\right|_{\mathrm{T}_{\mathrm{c} 1}} ^{\mathrm{T}_{\mathrm{c} 2}}, \mathrm{~T}_{\mathrm{c} 1}<\mathrm{T}_{\mathrm{c} 2} ;
$$

- for the first and second temperature ranges:

$$
\begin{aligned}
& e_{c}=\left.\left(\mathrm{T}_{\mathrm{c} 2}-\mathrm{T}_{\mathrm{c} 1}-\mathrm{T}_{\mathrm{o}} \ln \frac{\mathrm{T}_{\mathrm{c} 2}}{\mathrm{~T}_{\mathrm{c} 1}}\right) \sum_{\mathrm{i}=1}^{\mathrm{n}} \mathrm{CP}_{\mathrm{ci}}\right|_{\mathrm{T}_{\mathrm{c} 1}} ^{\mathrm{T}_{\mathrm{c} 2}}+ \\
& +\left.\left(\mathrm{T}_{\mathrm{c} 3}-\mathrm{T}_{\mathrm{c} 2}-\mathrm{T}_{\mathrm{o}} \ln \frac{\mathrm{T}_{\mathrm{c} 3}}{\mathrm{~T}_{\mathrm{c} 2}}\right) \sum_{\mathrm{i}=1}^{\mathrm{n}} \mathrm{CP}_{\mathrm{ci}}\right|_{\mathrm{T}_{\mathrm{c} 2}} ^{\mathrm{T}_{\mathrm{c}}}, \mathrm{T}_{\mathrm{c} 1}<\mathrm{T}_{\mathrm{c} 2}<\mathrm{T}_{\mathrm{c} 3}
\end{aligned}
$$

- for (k-1) temperature ranges:

$$
\begin{aligned}
& e_{c}=\sum_{j=1}^{j=k-1}\left[\left.\left(\mathrm{~T}_{\mathrm{cj}}-\mathrm{T}_{\mathrm{c}(\mathrm{j}-1)}-\mathrm{T}_{\mathrm{o}} \ln \frac{\mathrm{T}_{\mathrm{cj}}}{\mathrm{T}_{\mathrm{c}(\mathrm{j}-1)}}\right) \sum_{\mathrm{i}=1}^{\mathrm{n}} \mathrm{CP}_{\mathrm{ci}}\right|_{\mathrm{T}_{\mathrm{c}(\mathrm{c}-\mathrm{l})}} ^{\mathrm{T}_{\mathrm{cj}}}\right]+ \\
& +\left.\left(\mathrm{T}_{\mathrm{ck}}-\mathrm{T}_{\mathrm{c}(\mathrm{k}-1)}-\mathrm{T}_{\mathrm{o}} \ln \frac{\mathrm{T}_{\mathrm{ck}}}{\mathrm{T}_{c(\mathrm{k}-1)}}\right) \sum_{\mathrm{i}=1}^{\mathrm{n}} \mathrm{CP}_{\mathrm{ci}}\right|_{\mathrm{T}_{\mathrm{c}(\mathrm{k}-\mathrm{l})}} ^{\mathrm{T}_{\mathrm{ck}}}, \mathrm{T}_{\mathrm{c}(\mathrm{k}-2)}<\mathrm{T}_{\mathrm{c}(\mathrm{k}-1)}<\mathrm{T}
\end{aligned}
$$

- for $\mathrm{k}$ temperature ranges:

$$
e_{c}=\sum_{j=1}^{j=k}\left[\left.\left(\mathrm{~T}_{\mathrm{cj}}-\mathrm{T}_{\mathrm{c}(\mathrm{j}-1)}-\mathrm{T}_{\mathrm{o}} \ln \frac{\mathrm{T}_{\mathrm{cj}}}{\mathrm{T}_{\mathrm{c}(\mathrm{j}-1)}}\right) \sum_{\mathrm{i}=1}^{\mathrm{n}} \mathrm{CP}_{\mathrm{ci}}\right|_{\mathrm{T}_{\mathrm{c}(\mathrm{j}-1)}} ^{\mathrm{T}_{\mathrm{cj}}}\right], \mathrm{T}_{\mathrm{c}(\mathrm{k}-1)}<\mathrm{T}_{\mathrm{ck}}
$$

The initial and final temperature of the heat fluxes in the input data matrices (3) and (4) are divided into temperature intervals in the matrix (5) with allowance for the temperature increase. The functional dependences (6 and 7) are composite curves that sequentially summarize the exergy over each temperature range.

\section{Conclusions}

Exergy pinch analysis allows you to efficiently use the energy and resources of heating equipment. The 
presented mathematical model allows you to automate the construction of composite curves, avoiding errors and inaccuracies. To optimize the heat exchange system by the exergy pinch method, it is necessary:

1) Determine the flow exergy, you can use the device for measuring exergy (Russian Patent No 2702701 by Lebedev V A and Yushkova E A);

2) Using a mathematical model to build composite curves of hot (6) and cold (7) flows;

3) Reduce the composite curves to $\Delta T$ min, taking into account the optimization criterion represented by formulas $(1,2)$;

4) Determine the optimal values of utilities (external energy carriers) and the values of the exergy of the composite curves.

\section{References}

[1] A. Bahadori, Oil and Gas Pipelines and Piping Systems, 269-284 (2017). DOI: 10.1016/B978-012-803777-5.00010-1.

[2] T. Nguyen, T. Fülöp, P. Breuhaus, B. Elmegaard, Life performance of oil and gas platforms: Site integration and thermodynamic evaluation, Energy, 73, 282-301 (2014). DOI: 10.1016/j.energy.2014.06.021.

[3] T. Morosuk, G. Tsatsaronis, Splitting physical exergy: Theory and application, Energy, 167, 698-707. DOI 10.1016/J.ENERGY.2018.10.090.

[4] G. Chehade, I. Dincer, Exergy analysis and assessment of a new integrated industrial based energy system for power, steam and ammonia production, Energy, 116277, 2019. DOI: 10.1016/J.ENERGY.2019.116277.

[5] J. Rashidi, C. Yoo, Exergy, exergo-economic, and exergy-pinch analyses (EXPA) of the kalina power-cooling cycle with an ejector, Energy, 155, 504-520 (2018). DOI: 10.1016/J.ENERGY.2018.04.178.

[6] E. Trinklein, G. Parker, T. McCoy, Modeling, optimization, and control of ship energy systems using exergy methods, Energy, 191, 116542. DOI: 10.1016/J.ENERGY.2019.11.

[7] D. Olsen, Y. Abdelouadoud, P. Liem and B. Wellig, The Role of Pinch Analysis for Industrial ORC Integration, Energy Procedia, 129, 74-81 (2017). DOI: 10.1016/J.EGYPRO.2017.09.193.

[8] A. Dimian, C. Bildea, A. Kiss, Pinch Point Analysis, Computer Aided Chemical Engineering, 35, 525-564 (2014). DOI 10.1016/B978-0-444-62700-1.00013-9.

[9] I. Dincer, M. Rosen, Exergy, Elsevier Ltd (2007). DOI: 10.1016/B978-0-08-044529-8.X5001-0.

[10] E.A. Yushkova, V.A. Lebedev, Exergy analysis of the boiler using the pinch method, News of higher educational institutions, ENERGY PROBLEMS, 21, 4, 58-65 (2019). DOI: 10.30724/1998-9903-2019-21-4-58-65.

[11] E.A. Yushkova, V.A. Lebedev, Exergy pinch analysis of the primary oil distillation unit, $\mathrm{J}$.
Phys.: Conf. Ser., 1399, 044072. DOI:10.1088/1742-6596/1399/4/044072.

[12] T.N. Mitusova, N.K. Kondrasheva, M.M. Lobashova, M.A. Ershov, V.A. Rudko, Influence of dispersing additives and blend composition on stability of marine high-viscosity fuels, Journal of Mining Institute, 228, 722-725 (2017). DOI: 10.25515/PMI.2017.6.722.

[13] N.K. Kondrasheva, V.A. Rudko, D.O. Kondrashev, R.R. Konoplin, K.I. Smyshlyaeva, V.S. Shakleina, Functional influence of depressor and depressor-dispersant additives on marine fuels and their distillates components, Petroleum Science and Technology, 36, 2099-2105 (2018). DOI: $10.1080 / 10916466.2018 .1533858$.

[14] G. Priya, S. Bandyopadhyay, Multiple objectives Pinch Analysis, Resources, Conservation and Recycling, 119, 128-141 (2017). DOI: 10.1016/j.resconrec. 2016.02.005.

[15] R. Anantharaman, O. Abbas and T. Gundersen, Energy Level Composite Curves - A new graphical methodology for the integration of energy intensive processes, Applied Thermal Engineering, 26, 13, 1378-1384 (2006). DOI: 10.1016/j.applthermaleng.2005.05.029. 